Artigos da Sessão Livre 


\title{
UMA NOVA PAISAGEM AÇUCAREIRA: OS TÉCNICOS VERSUS OS MODOS TRADICIONAIS DE PRODUZIR ACCÚCAR NA ARGENTINA E NO BRASIL NAS PRIMEIRAS DÉCADAS DO SÉCULO XX
}

\author{
A new sugar landscape: the technicians versus the traditional ways \\ of producing sugar in Argentina and Brazil in the first decades of the \\ twentieth century
}

Roberta Barros Meira
Daniel Campi

RESUMO

O trabalho é uma pequena introdução sobre o papel dos técnicos na circulação de saberes nos espaços açucareiros. Nele, destacamos os escritos do engenheiro agrícola Pablo Lavenir, El cultivo de la caña y la elaboración del azúcar en las províncias de Tucumán, Salta Y Jujuy (1901), e do engenheiro Augusto Ramos, A indústria do açúcar em São Paulo (1902). O uso da História da Ciência nos permite perceber nessas obras não apenas os fatores de expansão da produção açucareira em áreas até então importadoras ou produtoras secundárias. Mas, igualmente, que a ciência que gerenciou os novos modelos de produção açucareira, resultou em uma cruzada contra os antigos métodos de cultivo e fabrico do açúcar e a favor de um ambicioso projeto de fortalecimento de uma recém-criada cultura açucareira científica e seus novos atores.

Palavras-chave: Circulação de saberes, paisagem açucareira, ciência .

\begin{abstract}
The work is a short introduction on the role of technicians in the circulation of knowledge in sugar spaces. In it we highlight the the writings of agricultural engineer Pablo Lavenir, El cultivo de la caña y la elaboración del azúcar en las províncias de Tucumán, Salta Y Jujuy (1901) and engineer Augusto Ramos, A indústria do açúcar em São Paulo (1902). The use of the History of Science allows us to perceive in these works not only the factors of expansion of sugar production in areas that until then had been importing or secondary producers. But also, that the science that managed the new models of sugar production, resulted in a crusade against the old
\end{abstract}

1 Bacharel e licenciada em História pela Universidade Federal Fluminense, mestrado e doutorado em História Econômica pela Universidade de São Paulo. Pós-doutoranda em ciências econômicas pela Universidad Nacional de Tucumán. Docente do programa de pós-graduação em Patrimônio Cultural e Sociedade e do Departamento de História da Universidade da Região de Joinville — Univille. E-mail: rbmeira@gmail.com.

2 Licenciado en Historia en la Universidad Nacional de Tucumán y Doctor en Geografía e Historia por la Universidad Complutense de Madrid, es Investigador Principal del CONICET y Profesor Titular de Historia Económica y Profesor Asociado de Historia de la Historiografía en la UNT. E-mail: danielcampi@yahoo.com.ar. 
methods of cultivating and manufacturing sugar and in favor of an ambitious project to strengthen a newly created scientific sugar culture and its new players.

Keywords: Circulation of knowledge; sugar landscape; science.

\section{Introdução}

As mudanças científico-tecnológicas na agricultura respondem algumas das questões que remodelaram a indústria açucareira nas primeiras décadas do século XX. Aliás, pode-se considerar que os escritos dos técnicos refletem com uma forte veemência uma época marcada pela valorização da ciência e o enaltecimento de novos atores. Assim, são esses trabalhos que se caracterizam por um linguajar extremamente técnico que deixam entrever o diálogo que se propagou por diversos países açucareiros. As crises que muitas vezes arrastam cenários de violências e sufocos econômicos e sociais, igualmente, podem abrir passagem para aplicar com menores restrições tudo o que passa a ser considerado adequado pelos recém-criados modelos produtivos. Nisto reside a singularidade dos relatórios científicos deixados pelo engenheiro Augusto Ramos ${ }^{3}$ e pelo engenheiro agrícola Pablo Lavenir ${ }^{4}$. Escritos com raízes fincadas na forte crise de 1901, as narrativas dos dois autores assumem uma posição que se sobressai por expor em um momento chave as ideias sobre os novos caminhos que deveriam ser seguidos pela indústria açucareira no Brasil e na Argentina.

Referindo-se à História da Agricultura, Ciro Flamarion Cardoso $(1979$, p. 15) destaca que um dos seus três tipos de estudo envolveria a História da Ciência e da Técnica. Para ele, cabe observar os métodos, os instrumentos e a organização da agricultura dentro dos eixos meio-ambiente/superfície cultivada e tecnologia agrícola. Tentando contemplar esses aspectos, nossa proposta trata de buscar melhor conhecer uma tendência bastante consistente de alteração nas paisagens açucareiras pelo fortalecimento de uma cultura agrícola científica e seus novos atores. Nesse sentido, os escritos técnicos permitem detectar a trajetória de uma agricultura que se transmuta e passa a pesar na mesma balança, de forma cada vez mais desequilibrada, os conhecimentos empíricos ditados por uma experiência de séculos e um saber sistematizado segundo os novos moldes da ciência agrícola moderna.

Por necessidade econômica, ou para fazer prevalecer o status dos novos atores nos espaços açucareiros, o equilíbrio dessa balança não pôde mais ser mantido, e pendeu progressivamente para o lado dos homens da ciência. Deste modo, nossa preocupação tem sido buscar entender o novo ordenamento e uma profunda re-hierarquização nos espaços açucareiros. Sobre tudo

3 Augusto Ramos era engenheiro, formado na Escola Politécnica do Rio de Janeiro. Dentre os muitos cargos de destaque, foi presidente da Sociedade Nacional de Agricultura e foi o inspirador do convênio de Taubaté. Experiência que levaria para formular o plano de defesa do açúcar, apresentado na Quarta Conferência açucareira em Campos, em 1911. Ademais, foi o representante do estado de São Paulo na Conferência açucareira da Bahia e do Espírito Santo. Dirigiu a Revista "O Fazendeiro". Também era proprietário da usina Cambaiba, em Campos. POLIANO (1945, p. 25).

$4 \mathrm{O}$ engenheiro agrícola francês Pablo Lavenir era formado no Instituto Nacional Agronômico de Paris. Ao ser contratado pelo Governo argentino, exerceu os cargos de docente do Instituto de Agronomía y Veterinaria de Santa Catalina, foi membro da Academia Nacional de Agronomía y Veterinaria e assumiu a direção do Laboratorio de Química de la Oficina Nacional de Agricultura e da Sección en la División de Química Agrícola e Industrial do Ministerio de Agricultura de la Nación. INST. DE SUELOS Y AGROTECNIA (1950, p. 11). 
isso, ainda se acrescente que as fontes consultadas revelam o fortalecimento de ideias e atitudes geradas no bojo de uma produção do discurso científico que também pode ser pensada como "controlada, selecionada, organizada e redistribuída por certo número de procedimentos" (FOUCAULT, 2012, p.8-9).

Ora, é muito provável que essas discussões refletissem o próprio processo de afirmação de uma imagem científica do mundo que na virada do século XIX para o XX atingiu fortemente o terreno da produção agrícola. Para Gildo Magalhães dos Santos Filho (2004, p. 40-53), o fortalecimento da distinção entre conhecimento científico e conhecimento popular ocorreu principalmente a partir da primeira metade do século XX. Da mesma forma, Boaventura de Souza Santos (2007, p. 25) defende a importância de reconhecer a "pluralidade de formas de conhecimento além do conhecimento científico", mas igualmente identifica o processo histórico de consolidação da ciência como único "conhecimento válido e rigoroso".

Neste particular, pode-se observar que a agricultura científica que ganhou força no Brasil e na Argentina foi constituída, em grande parte, da relação cada vez mais próxima com a agronomia e não mais com os conhecimentos tradicionais. Nesse cenário, a ciência agronômica declarava guerra aos saberes amealhados por gerações de agricultores. Assim, pode-se considerar que foi decorrente desta visão a depreciação do trabalho do agricultor que não empregasse a ciência e a tecnologia no plantio (CAPRA, 1982, p. 211-212). Tal constatação permite perceber uma evidente demarcação dos espaços de poder nas mãos dos técnicos, que mantém à margem os saberes tradicionais agrícolas. Além disso, com raríssimas exceções, foram privilegiadas pesquisas agronômicas que trabalhassem as contribuições valiosas do cruzamento de saberes, isto é, o que Boaventura de Souza Santos (2007, p. 29) chama de "ecologia de saberes".

Aliás, percebe-se mesmo a constituição do que podemos pensar como uma rede transnacional de saberes ligada à ciência agronômica, mas que não envolvia uma expressiva parte dos homens do campo. O conjunto dos informes técnicos, expedições de pesquisa feitas para outros países, trocas de dados entre as estações agronômicas e esferas governamentais demonstram a maior circulação de ideias e tecnologias que envolviam uma ampla gama de países. Nos momentos de crise, forjava-se mais fortemente um discurso de soluções que passavam pela promoção de métodos de exploração considerados mais racionais na agricultura e na pecuária, pela chancela dada pela ciência agronômica, pelo progresso dos meios de transporte e pela adoção de políticas de modernização (PLENCOVICH, 2003, p. 3). Por outro lado, certo é que as pesquisas sobre as ações dos homens da ciência - que almejavam controlar a agricultura na Argentina e no Brasil — poderiam ampliar a reconstituição histórica das disputas e negociações que envolveram a formação das novas paisagens açucareiras.

Mas lembra-se aqui que os estudos sobre os espaços açucareiros têm privilegiado as áreas de produção voltadas para o exterior (LINHARES, 1997, p. 10). A nosso ver, o problema, neste particular, é a perda de peças reveladoras de regiões pouco estudadas, deixando sombreados os lugares do açúcar ${ }^{5}$ que se escoraram prioritariamente em uma produção voltada para o mercado interno. Sabe-se que a realidade dos campos e das fábricas de produção voltadas para o mercado externo e para o mercado interno apresentam diferenças econômicas, tecnológicas, e mesmo políticas - se pensarmos, por exemplo, nos subsídios às exportações e na circulação de capitais. No entanto, algumas das novas questões que envolviam o açúcar eram comuns 
e foram desencadeadas na sua grande maioria por um fluxo de comparações que ensejaram reações similares em lugares distintos. ${ }^{6}$

A questão de o açúcar argentino e o de algumas regiões do Brasil, como era o caso do estado de São Paulo, serem estimulados pelo mercado interno, aclara, vez por ora, um movimento contínuo de transformação nos modos de fabricação e cultivo do açúcar - que estimulou ainda mais a expansão das áreas açucareiras. Esses espaços açucareiros diferenciados são elementos indicativos de que o fluxo de saberes empurra o açúcar para uma história comum de áreas que se tocam cada vez mais e que parecem fazer um movimento feito de uma só vez em conjunto.

\section{Sobre ciência, mercado e agricultura}

Como é sabido, na última metade do século XIX, a defesa da modernização açucareira criou raízes mais fortes no Brasil e na Argentina. Mas, também, é uma questão indiscutível que nos primeiros anos do século $\mathrm{XX}$, ambos os países se renderam à aridez do fato dos efeitos esmagadores de um crescimento da produção açucareira mundial de forma vertiginosa. Entre 1901-1910, a produção açucareira mundial aumentou 36,9\%, sendo que a cana teria um crescimento mais impressionante de $63,4 \%$ (de 3.925 .000 para 6.412 .000 toneladas) e a beterraba de 18,3\% (de 6.722.000 para 7.953.000 toneladas). Como era de se esperar, alguns territórios se destacaram mais, como Cuba e Java. ${ }^{7}$ Decorrente deste sucesso, os homens do açúcar começaram a ouvir com mais atenção os feitos que anunciavam o aniquilamento dos antigos modos de produção açucareira. Como quer que seja, tanto o açúcar de cana como o de beterraba sofreram intervenções legitimadas pelos novos especialistas para alcançarem o enorme progresso trazido pela ciência (MENDONÇA, 1998). Queremos frisar, também, que os avanços científico-tecnológicos nas práticas de produção do açúcar tinham todas as características de "uma faca de dois gumes". É certo que, por um lado, aumentava a produtividade. Mas, por outro lado, isso só poderia ocorrer às expensas de uma crise de superprodução que atingiria tanto os mercados mundiais como o comércio nacional e mesmo local do açúcar.

Não foi, portanto, por acaso que os anos mais exacerbados de crise, como 1901, seriam vistos como particularmente tocantes para fazer pender a balança para uma agricultura que se rendia à ciência como forma de construir um novo patamar para a produção açucareira. Esse ano seria marcado por uma queda brusca dos preços do açúcar, que, segundo Dé Carlí (1937, p. 28-29), teria o efeito de um verdadeiro crack. Alguns anos depois, caberia ao influente Miguel Calmon Du Pin e Almeida ${ }^{8}$ apontar que a situação do açúcar brasileiro em 1901 era de completa

6 Ginzburg (2004) deu ao conceito de circulação de saberes nova tintura ao relacionar as estratégias de transformação da Inglaterra em um ideal de país civilizado às conexões com outros lugares e tempos que a sustentam. Segundo ele, há que se ter em conta que nenhuma ilha é uma ilha.

7 Para este quadro contribui principalmente Cuba que teve um aumento da sua produção de 120\%; Java $76 \%$; Porto Rico $265 \%$, etc. (LIMA, 1913, pp. 100-101).

8 Miguel Calmon Du Pin e Almeida pertencia a uma proeminente família baiana, cursou engenharia na Escola Politécnica do Rio de Janeiro. Publicou diversos trabalhos sobre a indústria açucareira e assumiu diversos cargos públicos, entre os quais o de Ministro da Agricultura, Indústria e Comércio. Ademais, foi presidente da Sociedade Nacional da Agricultura entre 1921-23. (POLIANO, 1945) 
ruína.

Releva notar que o açúcar já tinha sofrido uma queda dos preços entre 1890 e 1894 nos mercados da Europa, o que se repetiria em 1901. Esta crise que afetou a Europa e os Estados Unidos piorou ainda mais o quadro de exportação do açúcar em países como a Argentina e o Brasil, que investiram na modernização do seu parque açucareiro nos anos anteriores. Segundo Dé Carli (1937, p. 28-29), o mais interessante é que a crise de 1901 atingiu mais intensamente aquela indústria semi-organizada, mais moderna, devido à necessidade de crédito avultado e a inversão de um grande capital. De 10 cruzeiros por arroba alcançados nos anos anteriores, em 1901, o açúcar chegaria a valer menos de 4 cruzeiros por arroba na praça do Recife.

Na base dos estímulos de criação de uma indústria açucareira moderna que diminuísse o gap tecnológico entre os diversos países açucareiros, os períodos marcados por baixas nos preços devido à superprodução expõem um cenário compartilhado que os países precisaram percorrer, necessariamente, em conjunto. É preciso lembrar, porém, como conclui Milton Santos (2006, p. 22), que a circulação do conhecimento e dos objetos técnicos não ocorre de forma homogênea ou uniforme. Essa questão é importante para pensar as mudanças na fabricação do açúcar, pois chama a atenção para as desigualdades "na história e no território, no tempo e no espaço". Da mesma forma, a circulação de conhecimentos e tecnologias faz parte de um movimento contínuo e seletivo, que aos poucos provoca profundas reorganizações territoriais, culturais, econômicas e paisagísticas.

Ademais, como se sabe, além da parte agrícola, o açúcar constitui na realidade um artigo manufaturado, cuja fabricação requer uma infraestrutura industrial bastante complexa. Mesmo quando praticado em moldes primitivos, essa fabricação envolve uma elaborada tecnologia de processamento (SZMRECSÁNYI, 1979, p. 42). A dependência das tecnologias estrangeiras era um obstáculo não tão fácil de ser contornado. Não se comprava apenas uma peça ou outra mais moderna para ser adaptada ao velho engenho. Os projetos, a mão-de-obra especializada e o maquinário passaram a ser, como defende Ruy Gama (1979, p. 255-256), "importados em pacotes (...) E com a perda da oportunidade de desenhar perde-se a autoridade do desígnio, da decisão. Ela é engolida nas novas formas de divisão do trabalho". O ambiente mais inovador e as patentes registradas pelas principais indústrias de base permaneciam, assim, sendo europeias ou norte-americanas.

E, acompanhando a história do açúcar no Brasil e na Argentina, percebe-se duas ideias bem marcantes: a necessidade premente de contornar o gap tecnológico que causava fortes prejuízos na balança comercial e a vinculação do progresso do setor açucareiro à alteração das formas de produção e cultivos existentes em ambos os países. Isso não quer dizer, no entanto, transformações rápidas ou uma transposição de modelos sem percalços e adaptações. O maior obstáculo, nesses processos de transformação agroindustrial almejado pelas elites e pelos técnicos, consistia justamente em ajustar a produção de um país aos novos modelos tecnológicos estrangeiros, desconsiderando a diversidade dos sistemas agrícolas, os fatores naturais e os quadros herdados das antigas metrópoles que geraram uma ordem difícil de ser quebrada no cenário nacional e internacional.

Patricia Juarez-Dappe (2010, p. 45) ressalta que na Argentina os produtores de açúcar tiveram que enfrentar um considerável incremento da produção no pós-1895, resultado da incorporação de modernas tecnologias. A produção açucareira argentina passou de 109.000 toneladas, em 1895, para 270.000 toneladas, em 1914. Entre 1895-1914, o número de plantadores de açúcar aumentou significativamente em Tucumán, enquanto a área cultivada 
com cana de açúcar quase dobrou, alcançando 90.848 hectares.

Embora os novos números parecessem prometedores de uma projeção de ambos os países no quadro mundial, os aspectos do vasto conjunto de fatores que compunham a produção açucareira moderna precisariam caminhar um pouco mais em sintonia. Mercado, ciência e agricultura formaram um tripé que teria que se ajustar às circunstâncias nacionais e a um conjunto de situações, as quais ocorreriam muitas vezes simultaneamente no Brasil, na Argentina, mas, igualmente, em Cuba, Java, Alemanha, França, Estados Unidos e em outros centros produtores de açúcar mais avantajados que os dois vizinhos sul-americanos. A racionalização do processo de produção e comercialização do açúcar passou a ser pensada pelas pessoas dotadas de conhecimentos técnico-científicos e que ocupavam cargos acadêmicos e administrativos. Exemplo disso seria Lavenir, em 1901, já trazer as ideias que coadunam ciência e açúcar ao destacar os males de um crescimento açucareiro sem planejamento e ao bel-prazer da natureza.

En lugar de buscar un suplemento progresivo de producción en el perfeccionamiento de los métodos de plantación y de cultivo y en un aumento razonable de las superficies cultivadas em cañaverales, se plantó cañas un poco en todas las partes, à menudo en terrenos poco adecuados para este cultivo y casi siempre sin las preparaciones culturales indispensables. Los efectos desastrosos de la sobreproducción pronto se hicieron sentir; la caña que se pagaba 18 hasta 25 centavos la arroba, em 1890-91 bajó rápidamente y en 1896-97 se la pagaba 5 y 6 centavos precios que no dejaban utilidad alguna à los cañeros. Muchos de ellos abandonaron los cañaverales casi sin cultivo y los resultados fueron, los que se debían esperar: disminución de los rendimientos y mala calidad de los productos (LAVENIR, 1901, p. 12).

Por outro lado, o cenário provocado pelos anos de crise muitas vezes foi perfeito para a promoção dos métodos considerados mais racionais para a fabricação e a comercialização do açúcar - que se inseriram com maior ou menor delongas no Brasil e na Argentina. Deve-se considerar que na Europa a ideia de progresso se aproximava da ciência. Aliás, generaliza- se a ideia de "progresso graças à ciência" ou por intermédio da "difusão da ciência" (SÁ, 2006, p. 92). Ocorre que essas ideias rapidamente se estenderam no Brasil e na Argentina, tendo forte repercussão no pensamento dos homens ligados ao açúcar. Não obstante não se possa negar que o conflito com os técnicos fosse relativamente forte em alguns momentos, as formas de ingressar no novo mundo açucareiro ${ }^{9}$ passavam por seguir as práticas dos centros comerciais internacionais e se adaptar às mudanças nas práticas de produção açucareira.

Foi em parte por força desta necessidade, muitas vezes aprofundada durante as crises, que as transformações no campo se fizeram sob a égide dos homens ligados às ciências agronômicas. Nesse sentido, conforme constata María Celia Bravo (2017, p. 20), em um livro da coleção "Historias Temáticas de Tucumán", a História Agrária deve ser pensada como uma arena de disputas pela presença de atores sociais de origens diversas. Segundo ela, ao lado de uma história de conflitos é possível ver consensos e realizações que forjaram práticas produtivas, comerciais e políticas públicas.

9 Considera-se aqui, metaforicamente, como "novo mundo açucareiro", o passo dado com a adoção dos primeiros engenhos centrais e das primeiras usinas. 
O que interessa, nesse momento, é perceber que os métodos tradicionais de cultivo não atendiam mais às demandas dos espaços açucareiros - frutos dos avanços tecnológicos na parte fabril e agrícola, mas, igualmente, das políticas protecionistas. A nova receita que se adaptava às circunstâncias e era almejada pelos técnicos estava compromissada com as ciências e as novas teorias rurais modernas, tendo como um dos seus modelos ideais a política francesa do retour à la terre ${ }^{10}$. Ora, há que se ter em conta outros fatores que também tiveram grande importância no período. Em verdade, como observou o famoso economista francês Yves Guyot (1901), os prêmios eram o centro da teia da questão do açúcar. ${ }^{11}$ Foi em parte por força desta articulação cada vez mais complexa entre o mercado e a produção que as crises podem ser vistas como acontecimentos legitimadores tanto das regulações econômicas como das mudanças nas formas de produção agrícola. ${ }^{12}$ Era exatamente isso que emanava do texto de Augusto Ramos quando ele tenta dar conta de propagar os princípios de uma agricultura racional, que se colava perfeitamente ao novo mundo do açúcar. Remediar a falta de conexão entre mercado e produção assumiu importância considerável no tratamento adequado das crises violentas.

É indispensável, porém, que essa expansão se faça convenientemente, obedecendo a uma boa orientação técnica e econômica, afim de não só colocar o Estado ao abrigo de crises violentas e graves, como também proporcionar à sua receita orçamentária, uma nova e valiosa fonte de renda, que tal deve ser uma das aspirações de toda e qualquer indústria, mesmo em um meio precário, quanto mais em se tratando do terreno paulista, fértil e apropriado (RAMOS, 1902, p. 3).

Prova disso, seria o alarme diante do crescimento do número de engenhos mal equipados e sem um bom manejo do cultivo da cana. O modelo idealizado de indústria açucareira de Augusto Ramos (1902) era o oposto da falta de avanço dos métodos de produção das unidades brasileiras que se mantinham tecnologicamente estagnadas, como o eram há 20, 30 ou 40 anos atrás. Segundo ele, este tipo de produção constituía um embaraço colossal, pois se estimava que o Brasil possuía 4000 fábricas açucareiras, produzindo 150 a 300 mil toneladas. Assim, imputava-se a culpa aos engenhos banguês pelo fato de o país possuir um número maior de fábricas do que o resto do mundo, cuja produção não seria inferior a 9 milhões de toneladas -

10 Ver: MENDONÇA, 1990.

11 Já em 1864, a Convenção Internacional colocava na pauta de discussões os prêmios de exportação e os impostos de entrada dos açúcares estrangeiros. Nesse sentido, deve-se levar em conta que a economia brasileira se restringia à exportação de basicamente oito produtos oriundos da grande lavoura. Em razão deste quadro econômico, o país ficava à mercê de transformações econômicas, como crises de produção ou de consumo que repercutiam no sistema mundial. Ver: MOURA FILHO (2001). 12 A defesa do atraso dos antigos métodos de produção seria contraposta às racionalidades econômicas puras (perseguição ao lucro, maximização de vantagens) (PESSANHA, 1997). 
30 vezes maior do que a do Brasil. ${ }^{13}$ Ou seja, fortalecia-se a ideia de que o atraso dos pequenos produtores de açúcar era a razão da perda do mercado externo. Augusto Ramos ainda apontava que:

Nesse meio século, nossa produção composta exclusivamente de engenhos de açúcar, fazendas de cana que fabricavam elas próprias o açúcar, por meio de uma instalação rudimentar de cozimento a fogo nu, cristalização do xarope concentrado por agitação a braços e formas de pães para o escoamento do melaço e branqueamento dos cristais. Eram eles e ainda são em cerca de 3000 . Perde-se 413.000 contos na fabricação se comparar com a extração obtida em Java, Cuba (...) (RAMOS, 1902, p. 35)

A percepção de que havia um gap tecnológico entre o Brasil e os outros países produtores se fez presente constantemente nas obras dos técnicos brasileiros. Como se vê no gráfico abaixo, o Brasil e a Argentina teriam que ter em conta um crescente aumento da produção no resto do mundo.

13 Não se pode esquecer que os dados apresentados por Augusto Ramos em 1902 refletem as dificuldades de consolidação da estatística mundial, mas principalmente no caso do Brasil. Nesse sentido, ressalta-se aqui as lacunas que caracterizam o trabalho dos técnicos, não sendo possível saber se o engenheiro teve acesso às estatísticas de todos os países produtores. Para Olivier Martins (2001), foi durante a segunda metade do século XVIII e nas primeiras décadas do XIX que emergiram os organismos oficiais encarregados de realizar as pesquisas estatísticas, de reunir as informações estatísticas e de assegurar sua difusão junto aos governantes e ao público. Mas, no Brasil, somente no final do século XIX foi criada a Repartição Especial de Estatística voltada para estruturar a estatística oficial acerca do comércio exterior. Essa Repartição foi pensada e dirigida por Sebastião Ferreira Soares - um dos pioneiros dos trabalhos estatísticos no país. No entanto, as inúmeras deficiências dos dados estatísticas no Brasil mantiveram-se como um problema nas décadas finais do Império e nas primeiras décadas da República. (SOARES, 2015, p. 149-182). Por outro lado, a comparação entre o Brasil e outros países feita por Augusto Ramos (1902, p. 5) refere-se especificamente aos entraves à adoção de processos mais modernos de produção mesmo após a criação dos engenhos centrais e usinas, uma vez que seus proprietários deixavam de "supri-la com os melhoramentos diariamente inventados no estrangeiro". A utilização do vocábulo fábrica pode ter se irradiado das mudanças do significado de algumas palavras, como aponta o Dicionário de sinônimos da língua portuguesa de Rocha Pombo (1914, p. 398). Há referências explícitas a isso quando ele destaca que fábrica ou usina (originária da palavra francesa usine), "está sendo mais usado que manufatura, para designar estabelecimento fabril onde o trabalho é feito mediante o emprego de aparelhos e maquinismos". 
Gráfico 1 - Principais produtores de açúcar

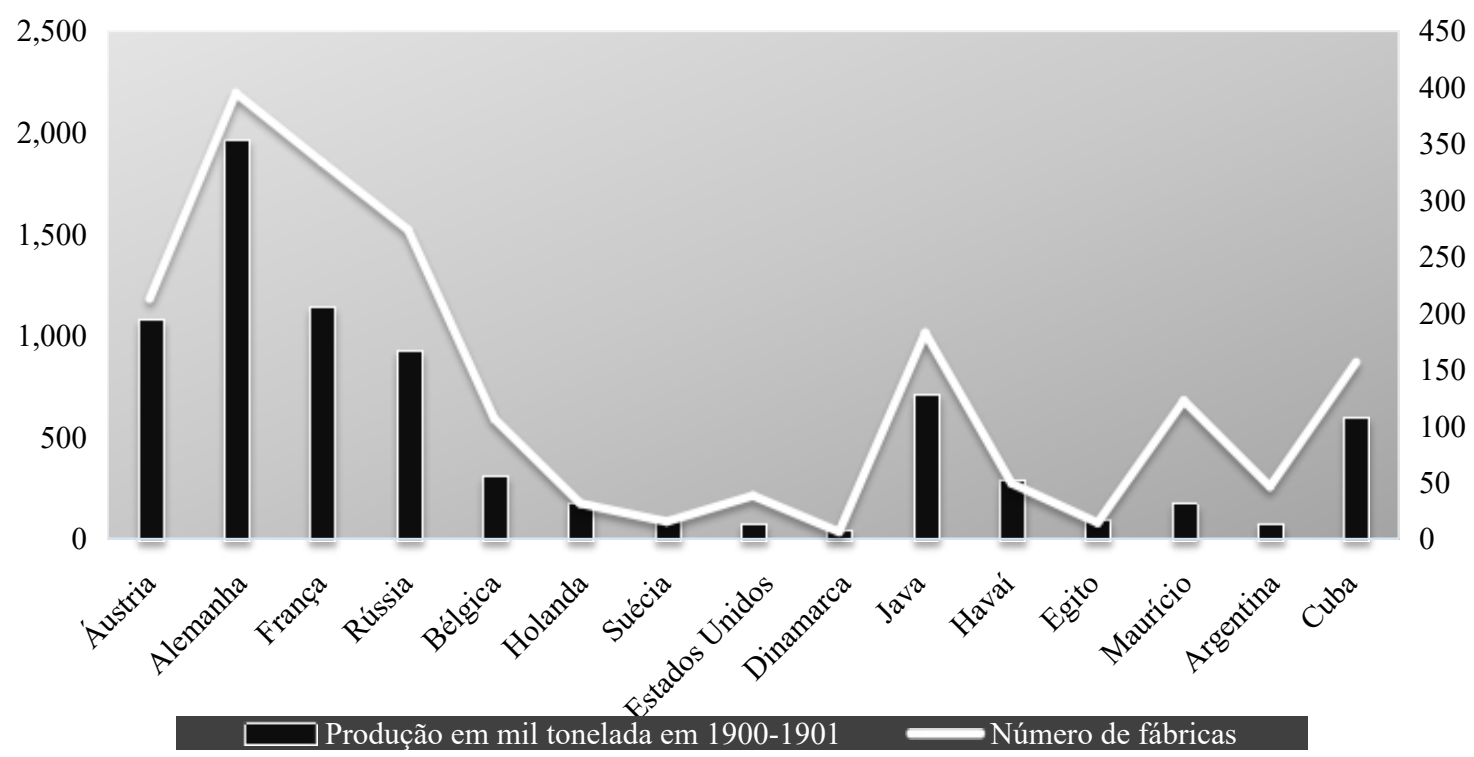

Fonte: RAMOS (1902, p. 9)

Nesse cenário, a Argentina produziu 80.000 t entre 1900 e 1901, com aproximadamente 47 fábricas. Enquanto Pernambuco, o maior estado produtor do Brasil, alcançou somente 100.000 t em 1902-1903 com 1.547 engenhos, sendo destes 1.500 engenhos de tacha. ${ }^{14}$ Já São Paulo produziria 10.200 t, com 19 engenhos, sendo 10 engenhos de tacha. A ideia esposada por Augusto Ramos era que São Paulo cuidasse de "imitar Java, cuja história açucareira é altamente instrutiva e convém ser contada" (RAMOS, 1902, p. 9). Aqui, caberia dar um pouco de atenção à tendência bem marcante de detalhar a evolução tecnológica, especialmente na parte fabril, forjada na Europa pelo açúcar de beterraba e, especialmente, em Java e Cuba, pelo açúcar de cana. Ora, tais estudos e comparações se inserem num quadro de circulação de saberes altamente especializados por agrônomos, químicos, mecânicos e engenheiros de diversos ramos que desenvolveram conhecimentos que se difundiram em grande escala a par das novas técnicas e maquinários. Mas, sem dúvida, a produção açucareira foi afetada pelas flutuações comerciais de mercados distantes ou nacionais. Como lembrava Lavenir (1901, p. 176), uma boa direção não mais consistia em moer cegamente a maior quantidade de cana possível em um tempo dado.

No Brasil, os dois mercados - interno e externo - assumiriam ao longo do tempo uma

14 Engenhos de tachas e os engenhos banguês representavam as formas rudimentares de produção de açúcar. Gileno Dé Carli (1985, p. 209) destaca que "o rendimento do engenho de tachas, em média, não excede de 45 quilos de açúcar bruto e 15 quilos de açúcar em mel, por tonelada de cana. A razão é que, além de outros fatores, as moendas somente extraem de 35 a 55 do peso bruto da cana (...) A primeira tacha recebe o caldo frio e devido à ação branda do fogo, começa a eliminação de impurezas, que são separadas com auxílio de espumadeiras de cobre (...) Depois de descachado o caldo, ele é passado por meio de canecos de madeira ou cobre para a caldeira, onde é alcalinizado — sem medida — e atuando o fogo mais energicamente, entra em ebulição (...) Depois de completo o cozimento, o xarope passa para a tacha de esfriar, onde demora cerca de 30 minutos, sendo então batido. Meio resfriado, é levado para as formas onde demora 10 dias escorrendo." 
relação de complementaridade - mas cujo ponto de apoio principal era incontestavelmente o consumo nacional. Como nos lembra Queda (1972, p. 53), a decadência da indústria açucareira brasileira se explica tanto pelo movimento da economia capitalista mundial como pela incapacidade de seguir o surto tecnológico inovador que ocorreu em outros países. O açúcar seria um produto marginal de exportação, sendo que em 1905 o Brasil já consumia $72 \%$ da sua produção. Nessa guerra de várias frentes, o açúcar de melhor qualidade produzido nas usinas disputava o mercado doméstico com o açúcar dos atrasados banguês. Ou melhor, a preocupação não se restringia à falência destes engenhos banguês, mas abarcava também a disputa por um mercado ainda pendente de garantias no mercado interno para o açúcar produzido pelas usinas.

Não se poderia também esquecer que o Brasil enfrentava várias impeditivos para alçar uma posição de destaque no mercado externo pelas relações estabelecidas entre os centros consumidores e produtores do açúcar de cana oriundos das relações neocoloniais e, igualmente, pelo aumento da produção do açúcar de beterraba na Europa (MOURA FILHO, 2007). Devese lembrar de que, mesmo antes da reorganização da indústria açucareira, a produção sempre excedia o consumo, ou seja, era necessário exportar para estabelecer um equilíbrio entre o volume das safras e a demanda interna, estabilizando os preços no mercado nacional. $\mathrm{Na}$ prática, a solução mais simples, isto é, exportar, nem sempre era uma tarefa fácil. Em 1892, o Centro da Indústria e Comércio de Açúcar do Rio de Janeiro queixava-se que o açúcar brasileiro já não tinha garantia de colocação nem na América do Sul nem na Europa. O envio do açúcar brasileiro para os Estados Unidos também estava limitado pela concorrência cubana que contava com tarifas aduaneiras mais baixas. Essa vantagem no mercado americano já se evidenciava nos acordos de reciprocidade para o comércio e navegação assinados ainda no período de colonização espanhola:

Em virtude da autorização outorgada pelo governo espanhol pelo art. $3^{\circ}$ da lei de 10 de junho de 1882, se aplicarão desde já os direitos da terceira coluna das tarifas de alfândega de Cuba e Porto Rico, o que implica a supressão do direito preferencial de bandeira aos produtos e procedência dos Estados Unidos da América do Norte. Em compensação, o Governo dos Estados Unidos suprimirá os adicionais de 10\% ad valorem sobre os produtos de procedência de Cuba e Porto Rico com a bandeira espanhola. (CICA, 1892, p. 30).

A abolição do tratado Blaine-Mendonça ${ }^{15}$ após quatro anos, em 1894, entre Brasil e Estados Unidos e os receios gerados pela Convenção de Bruxelas em 1901 pela adoção ou não dos prêmios açucareiros levaria os produtores de açúcar brasileiros a adotar uma política externa extremamente cautelosa. O receio do aprofundamento da crise pela perda do restrito mercado

15 O tratado Blaine-Mendonça permitia ao açúcar brasileiro entrar nos Estados Unidos livre de impostos, em troca de concessão de um privilégio similar no Brasil para os produtos industrializados exportados pelos Estados Unidos. John Schulz (2013, p. 104) defende que apesar de que tenha sido fortemente atacado pela imprensa brasileira no seu primeiro ano, esse acordo foi bastante vantajoso aos interesses açucareiros brasileiros, que puderam contar nestes quatro anos com um expressivo crescimento das suas vendas para o Estados Unidos. 
externo gerou a postergação da assinatura do Acordo ${ }^{16}$. Embora Augusto Ramos (1911) fosse um forte defensor dos prêmios no Brasil nos mesmos moldes aplicados na produção cafeeira, um conjunto de situações, que refletiram na punição do protecionismo adotado por alguns países, constituiu um formidável empecilho para os seus defensores colocarem suas ideias em prática. Aliás, a Argentina seria considerada por alguns como um exemplo de perigo da adoção das políticas de proteção açucareira.

É preciso tornar saliente que a Argentina pode elevar ao duplo a sua atual produção. Se hoje ela exporta somente 14 mil toneladas de açúcar, já

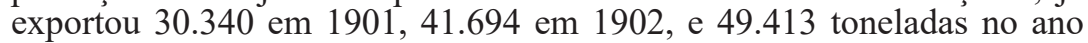
anterior, na última safra exportou 50.000 toneladas. A diminuição de exportação do ano último (1904) proveio de sua legislação especial que impunha um direito de 15 centavos por quilograma sobre $25 \%$ do açúcar produzido no país que equivale a um imposto ou prêmio de exportação do açúcar de 15,25 centavos por quilograma de açúcar. Por isso, os Estados Unidos, pelo seu departamento, fixaram o direito compensador a receber pelo açúcar argentino importado pela União em 15,25 centavos libra ou por outra, 56 fr. por 100 quilogramas, e a Inglaterra por sua vez, em virtude da Convenção, trancou os seus mercados ao açúcar de sua procedência. Agora (...) o Governo argentino baixou um decreto suspendendo na República todas as taxas e todo drawback sobre o açúcar, o quer dizer, que extinguiu os prêmios e procura assim entrar no Convênio. (BRASIL, 1905, 62)

Como quer que seja, embora a realidade argentina possuísse outras características peculiares em relação ao Brasil, a sua dependência em face do mercado interno era marcante ${ }^{17}$. À vista do exposto, pode-se perceber que uma das diferenças mais destacadas em relação ao Brasil era possuir um número pequeno de engenhos, que tenderam a diminuir à medida que a modernização avançava. De fato, como aponta Noemí Blacha (1991, p. 19-60), em 1913 o número de engenhos era de 43 — quase a metade dos existentes em 1877. Ademais, o terreno das disputas com os proprietários dos grandes engenhos se dava mais ao nível dos plantadores de cana do que das pequenas unidades de produção, como era o caso do açúcar brasileiro. Mas as condições entre ambos os países não diferiam se olharmos para as flutuações dos preços gerados por um consumo que se restringia ao mercado interno. Também consideramos importante o fato dos discursos dos homens do açúcar argentinos e brasileiros enfatizarem a necessidade de

$16 \mathrm{O}$ objetivo da Inglaterra em estabelecer o acordo de Bruxelas era rivalizar com a política econômica açucareira norte-americana. Nesse período, os Estados Unidos já havia estabelecido tarifas preferenciais e de acordos bilaterais de comércio, como os que vinham estabelecendo no caso do açúcar, com alguns países recém-libertos do colonialismo europeu, com alguns países latino-americanos de sua área de influência, e mesmo com nações europeias industrialmente atrasadas: Espanha, Cuba e Filipinas, México, Peru e Argentina. A Inglaterra buscava, desse modo, enfrentar o fechamento do mercado norte-americano e a inclusão nele de outras áreas do comércio mundial (GNACCARINI, 1997, p. 317). Em 1906, depois de anos de indecisão, o Brasil passou a ser signatário do Acordo de Bruxelas. No entanto, as expectativas não foram alcançadas. Mormente o país aderir à Convenção de Bruxelas por poucos anos, de 1906-1910, não ocorreu nenhum aumento significativo das exportações brasileiras como previram os seus defensores (IAA, 1972).

17 O processo de modernização colocado em marcha na Argentina aproximou-se consideravelmente mais do caso paulista. Embora São Paulo tenha assumido definitivamente o seu posto de principal produtor açucareiro nacional a partir da década de 1950 - escorado no crescimento do seu próprio mercado interno - , a construção da moderna base técnico-científica dos seus grandes engenhos centrais/usinas foi posta em marcha ao mesmo tempo que nas regiões açucareiras argentinas, como Tucumán. Ou seja, no final do século XIX e na primeira metade do século XX. Por outro lado, a região Nordeste do Brasil teria seu crescimento e modernização obstaculizado pela dependência do mercado externo e pela forte concorrência no mercado externo e interno. 
reduzir os custos de produção e melhorar as práticas de cultivo. Certo é que ambos os países tiveram também o seu aumento de produção ligado ao número sempre crescente de hectares plantados. Lavenir (1901, p. 221), como bom engenheiro químico, ressaltava que era à falta de direção ilustrada pela química que se devia a maior parte do atraso considerável da indústria açucareira da cana, se comparada à da beterraba. Assim como o ainda baixo investimento na melhoria da lavoura canavieira.

Por outro lado, no Brasil, era possível perceber de forma mais nítida o que Fernando Azevedo (1948, p. 221) consideraria um "estranho espetáculo". Isto é, a formação de uma paisagem açucareira mista, gerada por transformações muito lentas e a mescla entre os antigos e os novos sistemas de produção. É preciso que se atente, também, que a pouca representatividade no mercado mundial não significou um estancamento do processo de modernização e crescimento da capacidade produtiva dos engenhos. Gnaccarini (1997, p. 318-321) relata que na parte fabril as usinas e os bangues brasileiros se diferenciavam pelo emprego ou não dos novos equipamentos industriais. Mas percebe um movimento progressivo dos pequenos engenhos serem substituídos pelas usinas. Esse processo foi viabilizado tanto pela incorporação das terras dos pequenos engenhos como pela melhora nas suas técnicas de produção.

A explicação para esta crescente demanda por transformações pode ser atribuída às formas comerciais singulares que assumiu o mercado açucareiro com o aumento da produção do açúcar de beterraba e de cana. Aqui houve dois processos, entrelaçados, mas distintos. A variante econômica - o mercado interno ou externo - permanece como um dos pontos principais. Mas, de modo algum, pode-se esquecer um conjunto de ideias que circulavam tanto sobre a parte fabril quanto agrícola do açúcar, cujo suporte passou a ser dado pelas ciências agronômicas.

É preciso notar, como defendido por Peter Eisenberg (1977, p. 44-235), que o açúcar de beterraba europeu tomou os clientes tradicionais do açúcar de cana. As preocupações com as questões econômicas estabeleceram as principais justificativas que criaram uma teia em torno de fatores tecnológicos considerados como uma das principais armas na "guerra" entre a beterraba e a cana. Se o gap tecnológico com relação ao açúcar de beterraba foi sendo paulatinamente contornado pelos canavieiros, os técnicos envolvidos no fabrico do açúcar de cana foram também alçados a uma posição de detentores da vanguarda tecnológica e passaram a propagar ideias e modelos atrás de si.

Seria difícil não levar em conta, por exemplo, a influência de Álvaro Reynoso pelo número de referências ao seu trabalho comumente encontradas nas falas dos produtores de açúcar e técnicos, ao menos naqueles contemporâneos às suas publicações. Não é por acaso que Pablo Lavenir apresentou Reynoso como químico agrônomo ilustrado, reiterando as suas considerações sobre os enormes malefícios da adoção da mecânica moderna nas fábricas sem introduzir na mesma medida os avanços da ciência agronômica nos canaviais. ${ }^{18}$

No se puede económicamente cultivar mal, ni aun medianamente la caña de azúcar. El interés del fabricante y del productor de caña quedan íntimamente ligados a una buena producción, imposible sin un cultivo intensivo. La caña mal cultivada o mal plantada suministra productos muy

18 Vide: REYNOSO (1868). 
poco provechosos tanto en el ingenio como en el cañaveral (LAVENIR, p. 12).

Daniel Moyano (2001, p. 232-233) já havia observado que na Argentina o desenvolvimento da agricultura sobre bases científicas se concretizou tomando como modelos outros centros canavieiros, tais como Java, Havaí ou Luisiana. Desde o início do século XX, a ideia de contar com assessoramento científico permanente logrou ocupar um lugar central entre os donos de engenho, ou pelo menos em seu núcleo mais avançado. Se essas convulsões provocadas pela circulação de ideias eram semelhantes em quase toda a parte, representaram os ajustes às novas diretrizes que deveriam ser seguidas. E, no Brasil, por trás do afã por seguir os passos de Java, Augusto Ramos $(1902$, p. 12) revelava a relação complexa que se desenrolava com a ascensão dos técnicos. A principal questão planteada no seu texto para reforçar o "caminho absolutamente seguro" traçado pelos homens da ciência javaneses seria a resolução de problemas, tais como a possibilidade de contornar o esgotamento do solo com o uso de adubos, a superação das doenças pela reprodução por sementes ${ }^{19}$ e o desenvolvimento de variedades mais resistentes e mais ricas em sacarose.

Os técnicos moveram-se entre as fábricas e os canaviais de forma cada vez mais marcante. Vê-se que, progressivamente, a força da ciência agronômica passou a atuar nas novas práticas adotadas nos espaços açucareiros com grande intensidade. Nesse sentido, o objeto das preocupações e dos passos tanto dos técnicos como dos agricultores foram ponderados pelos aperfeiçoamentos na fábrica e na lavoura, em uma gama variada de países, não importando se a matéria-prima utilizada fosse a cana-de-açúcar ou a beterraba. Exemplo disso é a cuidadosa recomendação de Lavenir (1901, p. 14) ao tratar das melhorias do uso de arados em Salta, Jujuy e Tucumán, tomando como ponto de apoio os trabalhos de aragem adotados em Guadalupe, nas Antilhas, no Norte da França e na Espanha. Curiosamente, esse movimento envolveu tanto experiências bem-sucedidas como verdadeiros fracassos.

\section{Quando nem todo mérito se resume em saber copiar: o fracasso da difusão}

Na verdade, seguir modelos que levariam à perfeição não foi uma equação tão certeira como dois mais dois são quatro. Embora Augusto Ramos (1902, p. 9) defendesse que "hoje, para triunfarmos, não temos mais do que escolher o modelo culminante e copiá-lo", as situações e os resultados seriam diversos, como ele mesmo deixaria entrever na continuação do mesmo trabalho. Seria interessante incluir dentro dessas experiências o caso das fortes discussões

19 As sementes da cana foram consideradas estéreis por muito tempo. Nesse sentido, o sucesso das pesquisas realizadas pelas estações experimentais foi fundamental para o desenvolvimento de novas variedades. Alguns discursos proferidos durante $o$ Primeiro Congresso Nacional de Agricultura, em 1901, já ressaltavam o sucesso dessas experiências: "Desconhecida até bem pouco tempo, a possibilidade de obter das minúsculas sementes de flecha a reprodução da cana não é mais sujeita a dúvidas, e nesta metade última do século XIX, as ilhas Barbados, Guadalupe e Martinica têm presenciado tentames deste gênero seguidos do mais favorável êxito" (SNA, 1907, p. 02). 
sobre o processo da difusão voltada à extração da sacarose na agroindústria canavieira. ${ }^{20}$ Merece atenção o fato de podemos encontrar nesse rol de interessados pelo tema da difusão tanto Pablo Lavenir como Augusto Ramos. Mas importa mencionar que ambos utilizaram do conhecimento acumulado nas Antilhas, Maurício e mesmo na própria Argentina e no Brasil, para refutar as vantagens da difusão em detrimento do tradicional sistema das moendas. Ora, parece que as experiências argentinas e brasileiras não se diferenciaram muito, sendo que os engenhos inovadores tiveram rapidamente que voltar ao antigo processo das moendas. Neste caso, transplantar um método útil na fabricação do açúcar de beterraba para o processo produtivo do açúcar de cana não se mostrou benéfico. O investimento e a insistência de alguns técnicos e produtores de açúcar são explicados por Gileno De Carlí (1943, p. 25). Nesse caso, a solução para concorrer nos mesmos patamares com o açúcar de beterraba passava pela racionalização da produção de açúcar de cana, buscando alcançar "custos que descessem a um nível com que jamais a beterraba poderia concorrer".

A comparação entre os rendimentos criaria a percepção que não eram só os estímulos gerados pelos subsídios e privilégios nos mercados mundiais que definiriam os lugares ocupados pelos países do mapa açucareiro. Ora, Lavenir (1901, p. 68) esmerou-se em reproduzir detalhadamente em seu relatório os motivos que levaram os produtores de açúcar a investirem elevadas quantias, por sua conta e risco, em um modelo problemático no caso do açúcar de cana. Para ele, as perdas consideráveis de açúcar no bagaço obtido por pressão conduziram vários fabricantes a adotar o procedimento de extração por difusão.

\begin{abstract}
No cabe duda que la extracción del azúcar de la caña por difusión es el mejor método hasta hoy conocido pero el jugo que sale de los difusores es mucho más difícil de purificar que él obtenido por los trapiches aún con levigación, por esto se debe su poco éxito tanto en las Antillas, Mauricio, etc, etc., como en la República Argentina, donde se lo ha instalado sin previo estudio (LAVENIR, 1901, p. 83).
\end{abstract}

A difusão foi instalada em vários engenhos de Tucumán desde 1890. Exemplo disso foram os engenhos Lastenia, Concepción, Guzmann, Santa Ana e San Andrés. Alguns anos mais tarde, no entanto, só o engenho Concepcion continuava a utilizar esse sistema. Pois bem, segundo Lavenir (1901, p. 83), os próprios engenheiros de um dos maiores fabricantes europeus de maquinário, a casa Cail \& Cia., reconheciam que os resultados eram insatisfatórios e que seria melhor abandonar o procedimento. A possibilidade de melhor extração para contornar o baixo rendimento foi obstada por problemas que iam desde o custo e a manutenção do maquinário até os problemas com o maior uso de combustível. Ainda sobre as dificuldades na implementação deste sistema, Maria Celio Bravo (1998, p. 17-39) acredita que o uso e o

20 No processo de extração da sacarose da cana, conhecido como difusão, cortava-se a cana em talhadas de um a três milímetros de espessura, as quais se recolhiam a uma bateria de vasos chamados difusores, onde sofriam imediatamente a ação de uma corrente contínua de água pura. Em virtude do fenômeno físico de endosmose e exosmose, estabelecia-se naturalmente uma passagem simultânea do caldo sacarina para fora das células da cana e da água para dentro das mesmas células, de maneira que o caldo vai sempre empobrecendo e a água enriquecendo em açúcar, quando avança de um a outro difusor. No fim de certo tempo de trabalho, o caldo contido nas células das talhadas da cana do primeiro difusor tinha se transformado em água levemente açucarada e a água, que passou por elas, tem chegado ao último difusor transformado em caldo um pouco mais fraco que o natural, porém muito mais puro. Deste ponto em diante todos os trabalhos de fabricação do açúcar são idênticos nos dois processos, moagem e difusão. (MACOP, 1887). 
controle da água quando conectada à modernização tomou proporções maiores na Argentina do que em outras regiões produtoras de açúcar devido à escassez dos recursos hídricos. Assim, entende-se que uma inspeção ao Santa Ana, que apontava que o engenho consumia e poluía em esferas expressivas as águas dos rios do seu entorno, também pesasse nas decisões de retorno ao sistema de extração por moendas.

O abandono da difusão na Argentina não passou desapercebido nos estudos de Augusto Ramos (1902, p. 31). Motivos havia para não seguir pelo mesmo caminho, uma vez que grandes engenhos argentinos, fabricando diariamente perto de duas mil toneladas, tinham substituído a difusão pela multipressão em um curto período de tempo. Importa lembrar que no Brasil a difusão teria seu ponto alto ainda nas últimas décadas do século XIX com a propagação dos engenhos centrais. A baixa produtividade de alguns desses engenhos levaria à tentativa, por parte do Governo Imperial, de incentivar a difusão. A defesa teve continuação nos primeiros anos da República, que concedeu vantagens aos concessionários "que propuserem empregar o método da difusão nas fábricas a que o Governo considerar aplicável o mesmo sistema". ${ }^{21}$

O processo de difusão nem sempre contou com homens extremamente convictos da sua superioridade. $O$ engenheiro e diretor da repartição de agricultura e indústrias do Estado do Rio de Janeiro, Luiz de Castilho (1893), que estudou os resultados da difusão em Guadalupe, Luisiana e Cuba, acreditava que ela era coisa do futuro. Ademais, perguntava se os produtores de açúcar brasileiros deveriam se deixar convencer por inventores e fabricantes de maquinismos estrangeiros, fortemente interessados em vender o seu material. Alguns destes críticos utilizavam alguns relatórios técnicos internacionais para demonstrar a inferioridade deste sistema em relação às moendas. Estes técnicos comumente citados pelos seus pares brasileiros, como o engenheiro Louis Bom, natural de Guadalupe, argumentavam que este não era um sistema simples como se propagandeava, e que os resultados obtidos pela difusão eram inferiores em qualidade e quantidade quando comparados aos obtidos pelas moendas, sendo que alguns engenhos das Antilhas já estavam retornando ao antigo meio de extração. O engenheiro francês Henri Raffard (1888) também era contrário à aplicação da difusão, justificando a sua colocação pelos rendimentos baixos deste sistema nos Engenhos Centrais de Barcellos e Bracuhy.

Curiosamente, embora, as críticas não fossem poucas e os relatos de fracasso estivessem largamente divulgados, Augusto Ramos despendeu várias páginas para tratar da difusão. Convém observar que, para ele, as grandes dificuldades do açúcar brasileiro eram resultado da não adoção das evoluções técnicas estrangeiras, quer em relação ao açúcar de beterraba, quer em relação ao de cana. A sua fala deve ser considerada justamente quando ele destacou os magníficos resultados obtidos com a difusão no trabalho da beterraba. A necessidade de contornar a perda do açúcar no bagaço faria com que Cuba, Egito, Java e Estados Unidos, entre outros, experimentassem a difusão, atirando com "verdadeiro entusiasmo — para não dizer obsessão, crentes que não haveria nenhuma diferença entre a cana e a beterraba. Mas assim não aconteceu, pois não tardaram os desastres" (RAMOS, 1902, p. 25-26). O resultado

21 Já nos anos da Primeira República, o decreto nº. 819, de 4 de outubro de 1890, determinava facultativa a adoção do sistema da difusão, no entanto, estes engenhos ficavam obrigados a adotar o sistema da difusão logo que o Governo ordenasse a transformação, aumentando o respectivo capital de quanto fosse para isso indispensável; organizasse uma comissão agronômica permanente para acompanhar os engenhos que adotassem este sistema; e mais ainda, instituísse prêmios para as fábricas que adotarem o sistema de difusão e obtivessem da cana maiores porcentagens de açúcar. 
da comparação entre o uso da difusão no processo produtivo da cana e da beterraba, que pendia favoravelmente para a beterraba, pode ser visto nos dados apresentados pelo Barão de Barcellos.

\section{Gráfico 2 - Perdas no açúcar de cana e no açúcar de beterraba}

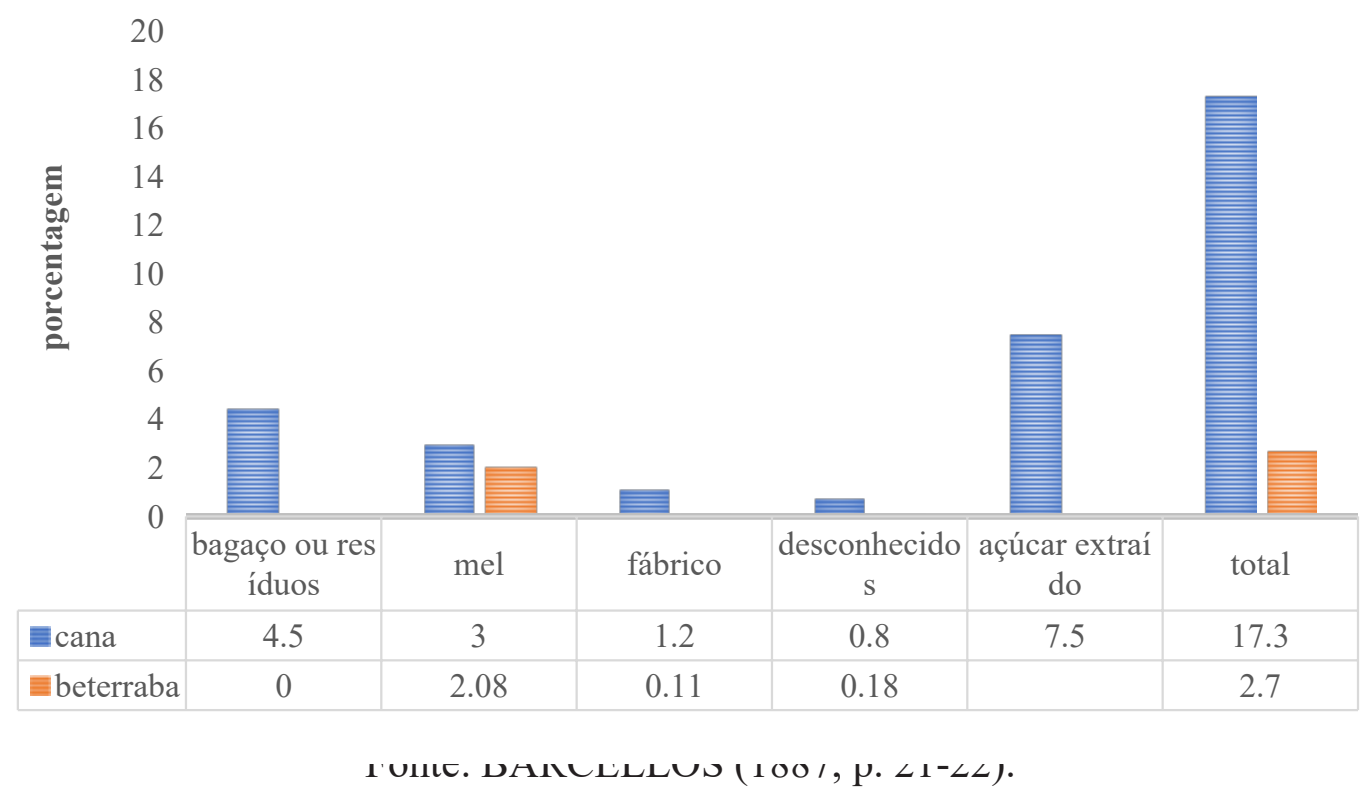

Para Augusto Ramos (1902, p. 32), o abandono do sistema de difusão pelos principais produtores de açúcar de cana - como Cuba, Havaí e Java - poderia servir de exemplo para o Brasil, que não deveria seguir um caminho diverso. Era necessário, mais do que extrair todo o açúcar do bagaço, produzi-lo de modo barato e prático. A difusão apresentava desvantagens sérias, como o grande aumento no custo da instalação, a produção considerável de mel e o sensível acréscimo do combustível necessário. Assim, ele defendia que "o objetivo final, iniludível, único, é produzir barato. É nisto que a difusão não alcança mais o primeiro lugar”. Talvez técnicos como Augusto Ramos quisessem apontar o que Vladimir Popov (2011, p. 53) consideraria fundamental para o crescimento manufatureiro - uma economia rural e uma produção açucareira que embebessem, como uma esponja, os princípios científicos de uma indústria açucareira dos seus sonhos. Ou seja, para cozinhar um bom prato, todos os ingredientes necessários devem estar na proporção certa - "if only one is under or overrepresented, the chemistry of growth does not happen".

Nesse sentido, pode-se falar de duas maneiras da circulação de saberes quando nos referimos ao açúcar: dizer, como Eisenberg (1977), que as inovações técnicas na produção do açúcar de beterraba se constituíram num dos aspectos chaves dessa lenta construção de 
saberes e tecnologias em movimento; ou então, dizer que o açúcar de cana nos anos seguintes assumiu os passos das pesquisas e avanços científicos — passando a competir com o açúcar de beterraba, desencadeando, igualmente, um fluxo de comparações e parâmetros ideais a se seguir. No caso da difusão, Lavenir (1901, p. 76) defendeu a opção pelas moendas, levando em consideração as experiências dos químicos do Havaí e da ilha Maurício. Enquanto Augusto Ramos considerou justamente o fato de que em Java todos preferiam a multipressão, embora conhecessem a difusão há mais de 14 anos. Mais significativa seria a reprodução do trabalho de um técnico alemão, analisando a experiência cubana no The International Sugar Journal, em 1900 .

This German authority declares that from a technical standpoint, The Cuban cane sugar industry was well advanced before the war. Central factories were well combined for economy of labor and fuel. Most of the factories worked a double series of mills with repression and in some few cases diffusion had been introduced, this method, however, having very lithe future (Apud. RAMOS, 1902, p.30).

Importa considerar que a "ciência moderna", que era usualmente identificada com a Europa (HAMBURGER, 1996), passava a ser reconhecida de forma cada vez mais recorrente - mas cedendo espaço, muitas vezes, aos avanços científicos amealhados nas paisagens canavieiras nacionais. Ao tratar da elaboração do açúcar na Argentina e no Brasil, Pablo Lavenir e Augusto Ramos defenderam a aplicação dos métodos utilizados na produção do açúcar de beterraba no fabrico do açúcar de cana. Mas não todos. A verdade é que se alargavam os pontos de vista e se argumentava em favor de uma "cópia" das contribuições potencialmente positivas dos dois tipos de açucares. As experiências serviram como modelo. As receitas que se adaptavam a qualquer circunstância também não eram consideradas mais como uma solução para todos os problemas dos países produtores de açúcar de cana.

Seria de se esperar que, ao se colocarem como os herdeiros do progresso científico, o interesse desses homens se chocaria com os antigos métodos de produção e comercialização. No campo do discurso, esses técnicos esmeraram-se em produzir trabalhos que demonstrassem a inviabilidade de promover o desenvolvimento da indústria açucareira ao se manter uma paisagem açucareira que era vista quase como um sortilégio. Nessa nova paisagem açucareira, a dimensão de sobrevivência do açúcar nacional vinculava-se de forma intrínseca ao fortalecimento dos técnicos, e subsequente a isso, à ideia de novos padrões de comportamentos econômicos e produtivos do açúcar — que englobavam tanto o ponto de vista da produção fabril e agrícola, assim como de sua comercialização.

\section{Conclusão}

Segundo Maria Ligia Prado (2005, p. 12), a história dos países latino-americanos passou por situações sincrônicas e semelhantes. Assim, diria ela que "em vez de manter os olhos fixos na Europa, é mais eficaz, para o historiador, olhar o Brasil ao lado dos países de colonização espanhola". A importância desta análise é repensar as origens de uma história 
comum, mas que ainda representa um dos grandes vazios da historiografia do açúcar, tanto a brasileira quanto a argentina. Em verdade, a História das Ciências e a História Econômica são duas das muitas estradas para desvendar o lugar dos técnicos no aparecimento de uma nova paisagem açucareira.

Aliás, Pablo Lavenir (1901, p. 184) termina o seu livro defendendo que era à falta da direção ilustrada pela química que se devia, em maior parte, o atraso considerável da indústria açucareira da cana quando comparada com a da beterraba. Por sua vez, Augusto Ramos (1902, p. 36) faz uma defesa aguerrida da fundação de um engenho modelo, que teria como um dos objetivos a criação de variedades de cana adaptadas ao clima de São Paulo, melhorando a planta, tal como se sucedeu em Java, Maurício, dentre outras regiões adiantadas. Convém observar que embora algumas dessas tecnologias e ideias fossem novas, desencadearam um fluxo de comparações e modelos a serem seguidos ou evitados. Ciência, mercado e agricultura eram ambientes diferentes, mas que se cruzavam cada vez mais. Essas relações parecem ser empurradas por uma circulação de saberes que se fortalece, criando redes externas e internas na tentativa de alcançar os patamares açucareiros considerados como ideais.

É preciso lembrar, porém, que a beterraba e a cana passaram a competir de forma cada vez mais acirrada, muitas vezes pelos mesmos mercados. Mas foram claramente os mercados internos, nacionais ou regionais, que deram fôlego e proteção às áreas da cultura da cana-deaçúcar que se diferenciavam por não produzirem para a exportação. Esboçava-se, assim, um fortalecimento da circulação dos saberes científicos nos diversos espaços açucareiros. Ademais, a insegurança gerada pelas crises de superprodução e os estudos comparativos dariam força às novas práticas de produção e comercialização. Em matéria de racionalização da produção, percebida como o máximo de rendimento com custos baixos, parece não haver diferenças expressivas no pensamento de Augusto Ramos (1902), voltado sobretudo ao estado de São Paulo, e no de Pablo Lavenir (1901), dedicado principalmente ao norte da Argentina.

De fato, a produção açucareira é feita da relação entre os seus atores, as paisagens construídas e reconstruídas e os acontecimentos do passado. No caso que aqui nos interessa, os técnicos foram os responsáveis, em grande parte, pela transformação do açúcar em uma agroindústria com os moldes atuais. Em consequência disso, as ciências agronômicas passam muitas vezes a ter o poder de redefinir a agricultura como cultura não mais vinculada somente aos homens do campo, solidificando também uma mentalidade vinda das universidades e centros de pesquisa. Nesse sentido, este artigo tentou dar contribuições a esse debate, demonstrado que o lugar que ocuparam os técnicos não foi fácil de ser alcançado e nem tal fato se processou do dia para a noite. Por outro lado, foi em grande parte por força da circulação de saberes e tecnologias que se criou um elo de ligação entre as diferentes regiões açucareiras. O resultado de tal política comparativa e de trocas seria uma reprodução parcial ou não dos discursos arados nos livros e relatórios agrícolas - baseados nas experiências de um desequilíbrio provocado por crises de superprodução que não estancaram em 1901. A ciência cercou o açúcar e os técnicos passaram a fazer parte do seu futuro. 


\section{Referências}

AZEVEDO, Fernando de. Canaviais e engenhos na vida política do Brasil. Rio de Janeiro: Instituto do Açúcar e do Álcool, 1948.

BARCELLOS, Barão de. A crise do açúcar: ligeiras considerações pelo Barão de Barcellos. Campos: Lit. e Tip. de Carlos Hamberger, 1887.

BLACHA, Noemí Gilbal de. Estado, modernizaticion azucarera y comportamento empresário en la Argentina (1876-1914): expansión y concentración de uma economía regional. In: Campi, Daniel (org.) Estudios sobre la Historia de la Industria azucarera argentina.Tucumán: Faculdad de Ciencias Economicas - UNT, 1991.

BRASIL. Trabalhos da Conferência Açucareira do Recife ( $2^{\circ}$ do Brasil- reunidos em 14 de março). Recife: Tip. do Diário de Pernambuco, 1905.

BRAVO, María Celia. Especialización azucarera, agua y política em Tucumán (1860-1904). Travesía, Tucumán, $\mathrm{n}^{\circ}$ 1, pp. 17-39, segundo semestre de 1998.

BRAVO, Maria Celia. La agricultura: actores, expresiones corporativas y políticas. Buenos Aires: Imago Mundi, 2017.

CAPRA, Fritjof. Ponto de mutação. São Paulo: Cultriz, 1982.

CARDOSO, Ciro Flamarion S. Agricultura, escravidão e capitalismo. Petrópolis: editora Vozes, 1979.

CASTILHO, Luiz de. Notas e fórmulas para uso dos fabricantes de açúcar, destiladores e refinadores e destiladores. Rio de Janeiro: Imprensa Nacional, 1893.

CICA. O Centro da Indústria e Comércio de açúcar do Rio de Janeiro. Rio de Janeiro: Companhia Tipográfica do Brasil, 1892.

DAPPE-JUAREZ, Patricia. When sugar ruled: economy and society in Northwestern Argentina, Tucumán, 18761916. Ohio: Ohio University Press, 2010.

DÉ CARLÍ, Gileno. O açúcar na formação econômica do Brasil in: Separata do Anuário Açucareiro. Rio de Janeiro: Instituto do Açúcar e do Álcool. Rio de Janeiro, 1937.

DÉ CARLI, Gileno. Gênese e evolução da indústria Açucareira de São Paulo. Rio de Janeiro: Editores Irmãos PONGETTI, 1943. 
DÉ CARLI, Gileno. História de uma fotografia. Recife: Editora ASA Pernambuco, 1985.

DIRECTORIA GERAL DE ESTATÍSTICA. Indústria assucareira no Brasil. Rio de Janeiro: Typ. da Estatística, 1919.

EISENBERG, Peter. Modernização sem mudança: a indústria açucareira em Pernambuco: 1840-1910. Rio de Janeiro: Paz e Terra; Campinas: Universidade Estadual de Campinas, 1977.

FOUCAULT, Michel. A ordem do discurso: aula inaugural no Collège de France, pronunciada em 2 de dezembro de 1970. São Paulo: Edições Loyola, 2012.

GAMA, Ruy. Engenho e tecnologia. São Paulo: Livraria Duas Cidades, 1979.

GINZBURG, Carlo. Nenhuma ilha é uma ilha: quatro visões da literatura inglesa. São Paulo: Companhia das Letras, 2004.

GNACCARINI, J.C. A. "A economia do açúcar: processo de trabalho e processo de acumulação" in: FAUSTO Boris (org.). História Geral da Civilização Brasileira, volume oito, Rio de Janeiro: Bertrand Brasil, 1997.

GUYOT, Ives. The Sugar Question in 1901. London: Hugh Press, 1901.

HAMBURGER, Amélia Império et al. A ciência nas relações Brasil-França (1850-1950). São Paulo: Edusp, 1996.

INSTITUTO DE SUELOS Y AGROTECNIA. Homenaje a Pablo Lavenir. Buenos Aires, Inst. de Suelos y Agrotecnia, 1950. (Publicación N 10). p.7-13.

Instituto do Açúcar e do Álcool. Brasil/ Açúcar. Rio de Janeiro: IAA, 1972.

LAVENIR, Pablo. El cultivo de la caña y la elaboración del azúcar en las províncias de Tucumán, Salta y Jujuy. Buenos Ayres: Imp. Y Enc. de P. Gadola, 1901.

LIMA, Pereira. O açúcar: apreciações sobre sua situação industrial. Rio de Janeiro: Tip do Jornal do Commercio, 1913.

LINHARES. Maria Yedda. História Agrária. In: CARDOSO, Ciro Flamarion e VAINFAS, Ronaldo (org.) Dominios da História: Ensaios da teoria metodológica. Rio de Janeiro: Editora Campus, 1997.

MACOP. Relatório apresentado à Assembleia Geral da $2^{\circ}$ Legislatura pelo Ministro e Secretário do Estado dos Negócios da Agricultura, Comércio e Obras Públicas Rodrigo Augusto da Silva. Rio de Janeiro: Imprensa 
Nacional, 1887.

MARTIN, Olivier. Da estatística política à sociologia estatística. Desenvolvimento e transformações da análise estatística da sociedade (séculos XVII-XIX). In: Revista Brasileira de História. V. 21, n. 4. São Paulo, p. 13-34, 2001.

MENDONÇA, Sonia Regina. Ruralismo: Agricultura, Poder e Estado na Primeira República. Tese (Doutorado em História), Universidade de São Paulo, São Paulo, 1990.

MENDONÇA, Sonia Regina de. Agronomia e poder no Brasil. Rio de Janeiro: Vício de Leitura, 1998.

MINTZ, Sidney. Sweetness and power: the places of sugar in modern history. New York: Viking, 1985.

MOYANO, Daniel Moyano. La escuela de arboricultura y sacarotecnia de Tucumán y su papel en el desarrollo agroindustrial de la província, 1880-1920. Travesía, nº 13, p. 229-246, 2001.

MOURA FILHO, Heitor Pinto de. Regulamentação Açucareira na França: uma longa história de proteção. In: Estudos Infosucro, Rio de Janeiro, Nuca-IE-UFRJ, n², setembro, 2001.

MOURA FILHO, Heitor Pinto de. "Os países latino americanos e a convenção açucareira de Bruxelas de 1902”. In: Anais do Primeiro Congreso Latinoamericano de Historia Econômica. Montevideo, 2007.

PESSANHA, Delma. Os fornecedores de cana e o estado intervencionista. Nitéroi: Eduff, 1997.

PLENCOVICH, María Cristina. La deriva de la educación agropecuaria en el sistema educativo argentino. Tesis en educación, Universidad Nacional de Tres de Febrero, Universidad Nacional de Lanus, 2003.

POLIANO, L. Marques. A Sociedade Nacional da Agricultura: Resumo Histórico. Rio de Janeiro: SNA, 1945.

POMBO, Rocha. Dicionário de sinônimos da língua portuguesa. Rio de Janeiro: Francisco Alves \& Cia. 1914.

POPOV, Vladimir. Development theories and developmente experience: half a century journey. Revista História e economia, São Paulo, v. 8, 2011.

PRADO, Maria Ligia Coelho. Repensando a História Comparada da América Latina. Revista de História, $\mathrm{n}^{\circ}$ 153, $\mathrm{n}^{\mathrm{o}} 2,2005$.

QUEDA, Oriowaldo. A intervenção do Estado e a agroindústria açucareira paulista. Tese de Doutorado, FFLCH, USP, 1972. 
RAMOS, Augusto Ferreira. A indústria do açúcar em São Paulo. São Paulo: Tip. Brazil de Carlos Gerke, 1902.

RAMOS, Augusto. Reunião açucareira. In A Lavoura. Boletim da Sociedade Nacional da Agricultura, v. 2, p. 1529, agosto-dezembro, 1911.

RAFFARD, Henri. Crise do açúcar e o açúcar no Brasil. Rio de Janeiro: Tip. Carioca, 1888.

REYNOSO, Álvaro. Tratado da cultura da cana de Açúcar. Rio de Janeiro: Tip do Imperial Instituto Artístico, 1868.

SÁ, Dominichi Miranda de. A ciência como profissão: médicos, bacharéis e cientistas no Brasil. Rio de Janeiro: editora Fiocruz, 2006.

SANTOS, Boaventura de Sousa. Para além do pensamento abissal: das linhas globais a uma ecologia de saberes. Novos estudos CEBRAP, n.79, p.71-94, 2007.

SANTOS, Milton. A natureza do espaço: Técnica e Tempo, Razão e Emoção. São Paulo: Editora da Universidade de São Paulo, 2006.

SANTOS FILHO, Gildo Magalhães dos. Ciência e ideologia: conflitos e alianças em torno da ideia de progresso. Tese (Livre Docência). Universidade de São Paulo. São Paulo, 2004.

Schulz, John. As crises financeiras da abolição. São Paulo: Universidade de São Paulo, 2013.

SZMRECSÁNYI, Tamás. O planejamento da Agroindústria canavieira do Brasil (1930-1975). São Paulo: Hucitec; Campinas: Universidade Estadual de Campinas, 1979.

SNA. Anais do Congresso Nacional de Agricultura instalado a 20 de setembro de 1901 no Rio de Janeiro. Rio de Janeiro: Imprensa Nacional, 1907.

SOARES, L. C. Sebastião Ferreira Soares e a introdução da ciência estatística no Brasil do Século XIX. Revista $I H G B$, Rio de Janeiro, a. 176, n. 467, abr.jun. 2015, pp. 149-182.

RECEBIDO EM: 15/01/2018 